\title{
The Moderating Effect of Moral Identity on the Relationship between Emotional Exhaustion and Budget Slack
}

\author{
Ying Tong, Manoch Prompanyo* \\ School of Management, Shinawatra University, Pathum Thani, Thailand \\ Email: tongying325@126.com, *manoch.p@siu.ac.th
}

How to cite this paper: Tong, Y., \& Prompanyo, M. (2021). The Moderating Effect of Moral Identity on the Relationship between Emotional Exhaustion and Budget Slack. Open Journal of Accounting, 10, 93-104. https://doi.org/10.4236/ojacct.2021.103008

Received: October 27, 2020

Accepted: July 5, 2021

Published: July 8, 2021

Copyright $\odot 2021$ by author(s) and Scientific Research Publishing Inc. This work is licensed under the Creative Commons Attribution International License (CC BY 4.0).

http://creativecommons.org/licenses/by/4.0/

\begin{abstract}
Emotional exhaustion, as a kind of exhausted negative psychological state, have an impact on individual work behavior, job performance, turnover rate, job satisfaction and so on. In the practice, the negative impact of budget slack on budget management cannot be ignored. The existence of budget slack makes the budget fail to achieve its proper function, which violates the planning function of the budget. The budget slack conceals the real resource demand, profitability and financial situation of the enterprise, which makes it impossible for the owner to make an accurate judgment and decision. However, the impact of emotional exhaustion on budget slack is unknown. This paper introduces the psychological state of emotional exhaustion into budget research and explores the causes of budget slack from internal psychology. Our results imply that when subordinates are emotionally exhausted, they tend to give up their insistence on honesty and prefer a relaxed budget. In addition, the moral identity negatively moderates the relationship between emotional exhaustion and budget slack of subordinate.
\end{abstract}

\section{Keywords}

Moral Identity, Emotional Exhaustion, Budget Slack

\section{Introduction}

Emotional exhaustion, as a kind of exhausted negative psychological state, have an impact on individual work behavior, job performance, turnover rate, job satisfaction and so on (Mitchell et al., 2017). Specifically, emotional exhaustion can reduce the self-management ability of employees, relax the high standards of 
their own, and may lead to some unethical behavior of employees (Lawrence \& Michele Kacmar, 2017). Moreover, long-term work stress leads to emotional exhaustion of employees, which leads to negative emotions such as depression, anger, irritability, so that employees cannot devote themselves to work or even get out of work, work engagement is reduced, and the performance of employees and organizations is reduced (Golparvar, 2015; Chen \& Qin, 2011; Maslach et al., 2001). Another scholar has shown that emotional exhaustion not only affects job performance but also affects employee job satisfaction and turnover rate (Tijdink, Vergouwen \& Smulders, 2014).

A great deal of empirical evidence has been shown that budget slack is common in organizations (Merchant, 1985; Merchant \& Manzoni, 1989). Scholars have also carried out extensive research on budget slack. The first theoretical foundation of budget slack is the principal-agent theory. However, in the process of formulation and implementation of budget, it is bound to be affected by human behavior and motivation. Human behavior and psychology are complex, principal-agent theory doesn't explain budget slack very well (Tayler \& Bloomfield, 2011; Davidson \& Stevens, 2013; Douthit \& Stevens, 2015). More and more scholars are trying to introduce human behavior, motivation and psychology into budget slack control (Libby \& Murray Lindsay, 2001; Webb, 2002; Stevens, 2002; Little et al., 2002). However, the impact of emotional exhaustion on budget slack is unknown.

In addition, in order to understand the relationship between emotional exhaustion and budget slack, this paper intends to further explore the impact of moral identity on the relationship between them. Moral identity is a kind of self-concept based on a series of moral characteristics (Aquino \& Reed, 2002). In this paper, subordinates who feel emotional exhaustion are affected by their moral identity when implementing the budget slack. Generally speaking, subordinates with high moral identity are more inclined to engage in moral behavior, so compared with employees with low moral identity, employees with high moral identity may reduce the effect of emotional exhaustion on budget slack.

Many scholars have studied the intermediate role of moral identity: moral identity can positively moderate or mediate positive moral behavior, such as organizational citizenship behavior (Liu et al., 2017), pro-social behavior (Yang \& Wang, 2015), ethical tendentious behavior, etc. Zhang \& Liao (2017) explored the influence mechanism of moral identity on the relationship between ethical leadership and ethical behavior of employees. Moreover, moral identity can negatively moderate or mediate negative unethical behavior of individuals. For example, Individuals with higher moral identity reduce network attacks (Yang \& Wang, 2015), reduce extreme antisocial behavior due to moral evasion (Zheng et al., 2016; Ormiston \& Wong, 2013; Kavussanu, Stanger, \& Ring, 2015), inhibit destructive or retaliatory behavior due to asymmetric information (Skarlicki et al., 2016). Wu et al. (2017) have explained the specific mechanism of moral identity in the relationship between organizational commitment and pro-organizational 
unethical behavior.

The next section discusses the relevant literature and theoretical foundation to develop the hypotheses. And then, proposes the research method and results from the analysis. The final section main concludes innovations and further research prospects in the future.

\section{Development of Hypotheses}

\subsection{Emotional Exhaustion and Budget Slack}

Emotional exhaustion can directly lead to unsafe behavior of employees (Ju, Qin, \& Xu, 2016). When subordinates are in emotional exhaustion, in order to avoid being punished for the decrease of performance, it is easy for the subordinates to make false reports or exaggerate his work performance to avoid punishment (Golparvar, 2015).

Emotional exhaustion, as a negative emotional state, can reduce the self-management ability of employees, relax the high standards of their own, and may lead to some unethical behavior of employees (Lawrence \& Michele Kacmar, 2017). Budget slack refers to the situation in which budget implementers deliberately overestimate expenditure, underestimate income or undervalue performance in the budget setting process (Yu et al., 2004). The problem of budget slack is not only the agent problem, but also the violation of social norms and deviant behavior (Deng et al., 2014). Kim, Hwang \& Lee (2008) supported when the subordinates is in the emotional exhaustion, its self-control ability will decline, which will affect its control of instinctive impulse, and then leading to the cheating behavior. For example, when subordinates are in the emotional exhaustion, they will give up their commitment to honesty and prefer instant rewards (Mazar et al., 2008), in the budget environment, do not report their own private information, and are not easy to restrict social morality, tend to treat the budget in a negative state.

In summary, we propose the following assumptions about the relationship between emotional exhaustion and budget slack and intend to test it. The following hypothesis is tested:

$\mathrm{H}_{1}$ : The emotional exhaustion positively affects budget slack.

\subsection{Moral Identity Moderating Effect}

The moral identity can moderate individual antisocial behavior, immoral behavior and other behaviors (Zeng, 2011). Moral identity can negatively moderate negative unethical behavior of individuals. For employees with high moral identity, even feel exhausted, they also make moral judgment based on their own moral cognition, think rationally and put an end to unethical behavior (Ormiston \& Wong, 2013). It is difficult for individuals with high moral identity to remove their moral responsibility by moral evading (Yang et al., 2010). Therefore, the higher the individual's moral identity, the less likely to choose negative behavior (Reynolds \& Ceranic, 2007). When subordinates in the emotional ex- 
haustion, subordinates with higher moral identity reduce negative behavior, for example network attacks (Yang \& Wang, 2015).

Moral identity can positively moderate negative behavior, for example cheating behavior (Reynolds \& Ceranic, 2007). Besides, there is a significant negative correlation between moral identity and budget slack (Stevens, 2002; Hobson et al., 2011). Because of the existence of moral identity, budget executors would subjectively partially sacrifice their personal interests to improve budget goals and reduce budget slack (Hobson et al., 2011).

In summary, we propose the following assumptions about the impact of moral identity on emotional exhaustion and budget slack and it is intended to be tested. The following hypothesis is tested:

$\mathrm{H}_{2}$ : The moral identity negatively moderates the relationship between emotional exhaustion and budget slack of subordinate.

We use descriptive statistics to analyses and explain the personal profile of the respondents. Moreover, we employed inferential statistics, including Pearson's Correlation, and Hierarchical regression, to test variables and to test the hypothesis at a significant level 0.05 using SPSS 22 statistical analysis software.

\section{Research Method}

\subsection{Participants}

Because in China the larger manufacturing enterprises are the first to put into the budget management system, and at present, they are the most extensive and mature enterprises in budget management practice (Yu et al., 2004). Besides, the production department is the most basic department for budget control (Subramaniam \& Mia, 2003). Therefore, we invited employees who are working in the production department of manufacturing industry in Beijing city. The survey was sent to 600 employees, and 400 questionnaires were valid. The questionnaire adopts the self-administered survey and is sent in the form of a network.

Descriptive statistical analysis is to explain the necessary data of the respondents, as shown in the following Table 1, by describes the classification and percentage of the four variables, including tenure, enterprise ownership and enterprise scale of the study samples to illustrate the reasonable sampling. This final sample was consisted of 44.5 percentage $(n=178)$ male respondents and 55.5 percentage (222) female respondents. There are a large proportion of respondents with mainly 5 - 10 years and more than 10 years, accounting for $32.5 \%$ and $31.3 \%$ respectively. In 400 research samples, state-owned enterprises were the main respondents, accounting for $63 \%(n=251)$. The proportion of respondents in non-state enterprises reached $37 \%(\mathrm{n}=149)$. Enterprise scale included 100 500 person $(\mathrm{n}=148,37$ percent), $500-1000$ person $(\mathrm{n}=161,40.25$ percent $)$ and more than 1000 person $(n=91,22.75$ percent). On the whole, the proportion of participants in the survey came from companies with a total of more than 500 people reached $63 \%$, accounting for the vast majority. 
Table 1. Demographic statistics.

\begin{tabular}{|c|c|c|c|}
\hline \multicolumn{4}{|c|}{$\begin{array}{l}\text { Personal Information, and Percentage of Participants from } \\
\text { Different Ownership and Scale of Industries }\end{array}$} \\
\hline & & $\mathrm{n}$ & Percentage \\
\hline \multirow{2}{*}{ Gender } & Female & 222 & $56 \%$ \\
\hline & Male & 178 & $44 \%$ \\
\hline \multirow{5}{*}{ Tenure } & less than 1 years (does not include 1 years) & 32 & $8 \%$ \\
\hline & 1 - 3 years (excluding 3 years) & 61 & $15.3 \%$ \\
\hline & $3-5$ years (excluding 5 years) & 52 & $13 \%$ \\
\hline & 5 - 10 years (excluding 10 years) & 130 & $32.5 \%$ \\
\hline & more than 10 years & 125 & $31.3 \%$ \\
\hline \multirow{2}{*}{ Ownership } & State-owned enterprises & 251 & $63 \%$ \\
\hline & Non-state enterprises & 149 & $37 \%$ \\
\hline \multirow{3}{*}{ Scale } & $100-500$ person & 148 & $37 \%$ \\
\hline & $500-1000$ person & 161 & $40.25 \%$ \\
\hline & more than 1000 person & 91 & $22.75 \%$ \\
\hline
\end{tabular}

\subsection{Measures}

\subsubsection{Emotional Exhaustion (Independent Variable)}

The emotional exhaustion indicates a negative psychological state of the employee. In this paper, the emotional exhaustion measurement scale in the MBI-GS scale compiled by Maslach et al. (1986) contains 9 items. Evaluating the emotional state of employee for nearly two months, the reliability and validity of the measurement scale was proved to be good (Zhang et al., 2014; Li \& Li, 2006). The 9 items of measurement scale are positive score. That is, the higher the score is, the higher the emotional exhaustion frequency. The reliability coefficient (Cronbach's $\alpha$ ) is 0.917 , which was higher than the acceptable standard of 0.70 , which indicate that the measurement of the variable had better measurement reliability. For example: my work leaves me physically and emotionally exhausted.

\subsubsection{Moral Identity (Moderator Variable)}

The moral identity refers to the degree of individual recognition of moral characteristics, which belongs to the individual level of research variables. In this paper the moral identity is measured by the measurement scale developed by Aquino and Reed (2000), which contains two dimensions, a total of 10 items. The most widely used measurement scale of moral identity is compiled by Aquino and Reed (2000). A number of scholars verified the reliability and validity of this measurement scale through empirical analysis (Yang \& Wang, 2015; Skarlicki, Jaarsveld, \& Shao, 2016; Passini, 2016). The measurement scale devel- 
oped by Aquino and Reed (2000) is divided into positive and negative score, in this, the positive score are 8 items, and the negative score are 2 items. Positive example: being someone with good qualities (e.g. helpfulness, honesty, etc.) is important for me. The negative example: it doesn't matter to me to be a person with these qualities. The reliability coefficient (Cronbach's $\alpha$ ) is 0.960 , which was higher than the acceptable standard of 0.7, which indicate that the measurement of the variable had better measurement reliability.

\subsubsection{Budget Slack (Dependent Variable)}

We used the measurement scale of 4 items developed by Onsi (1973) to measure the tendency of budget slack. Example items such as, "I usually set two kinds of budget standards, one for myself to discuss with subordinates (or colleagues), the other is to achieve budget goals more easily for myself to discuss with superiors" and "for budget matters that cannot be approved by formal method, I tend to find my own way according to the needs within the work unit". The reliability coefficient (Cronbach's $\alpha$ ) is 0.803 , which was higher than the acceptable standard of 0.70 , which indicate that the measurement of the variable had better measurement reliability.

\subsubsection{Control Variables}

Control variables are those that affect the results of the experiment except the independent variables. These variables are not the variables to be studied in this experiment. Previous studies have shown that employees' tenure can affect budget slack (Schatzberg \& Stevens, 2008), and the ownership and scale of the enterprise in which they work can also affect budget slack (Onsi, 1973). Based on this, we choose the three variables of employees' tenure, enterprise ownership and enterprise scale as the control variables of the study.

\section{Analysis and Results}

The Pearson correlation analysis is used to detect each variable and measure the relationship between all variables. The means, standard deviations and correlations of the variables are shown in Table 2. The results shows that there is a significant positive correlation between emotional exhaustion and budget slack $(r=$ $0.375, \mathrm{p}<0.01)$; there is a negative correlation between moral identity and emotional exhaustion $(\mathrm{r}=-0.173, \mathrm{p}<0.01)$. The correlation between these variables is consistent with the research hypothesis, which provides preliminary evidence for the verification of theoretical hypothesis.

In order to verify the moderating effect of moral identity on budget slack, according to the moderating test method of Wen et al. (2006), this paper sets budget slack as dependent variable and puts control variable (tenure, ownership and scale), preposition variable (emotional exhaustion), moderating variable (moral identity), and the interaction between preposition variable and moderating variable. At the same time, in order to disregarding the effect of multicollinearity among the explanatory variables, this paper standardizes the interaction terms 
Table 2. Correlation analysis of variables.

\begin{tabular}{lcrcccccc}
\hline \multicolumn{1}{c}{ Variables } & Mean & SD & 1 & 2 & 3 & 4 & 5 & 6 \\
\hline 1) Tenure & 3.64 & 1.283 & 1 & & & & & \\
2) Ownership & 0.63 & 0.483 & $0.117^{*}$ & 1 & & & & \\
$\begin{array}{l}\text { 3) Scale } \\
\text { 4) Emotional }\end{array}$ & 1.85 & 0.760 & 0.039 & 0.060 & 1 & & & \\
exhaustion & 3.27 & 0.907 & 0.058 & $0.113^{*}$ & $0.116^{*}$ & 1 & & \\
5) Moral identity & 3.19 & 0.986 & -0.016 & -0.015 & 0.086 & $-0.173^{* *}$ & 1 & \\
6) Budget slack & 3.20 & 0.836 & $0.265^{* *}$ & $0.179^{* *}$ & $0.192^{* *}$ & $0.375^{* *}$ & $-0.112^{*}$ & 1
\end{tabular}

*. The significance level of the mean difference was $0.05 .{ }^{*}$. The significance level of the mean difference was $0.01 . \mathrm{N}=400$. (1) Tenure is measured by " $1-5$ ". (2) Ownership of the enterprise is simplified into two categories: state-owned enterprises and non-state-owned enterprises, and measured by " 0 - 1 ". Scale of the enterprise is measured by " $1-3$ ", according to the large scale, medium and small scale of Chinese manufacturing enterprises.

between the preposition variable and the moderating variable.

The results of the hierarchical regression analysis for the moderating effect of budget slack are shown in Table 3. From Table 3 we can see that emotional exhaustion has a significant effect on budget slack $(\beta=0.334, \mathrm{p}<0.01)$. In the Step 1 , when only control variables (tenure, ownership and scale) are added, the $\mathrm{R}^{2}$ value of 0.123 indicates that emotional exhaustion can explain the change of $12.3 \%$ of the budget slack. On the basis of Step 1, add preposition variable (emotional exhaustion) and moderating variable (moral identity) to form Step 2. When the inference of control variables is excluded, the $\mathrm{R}^{2}$ value of 0.235 indicates that emotional exhaustion and moral identity can explain the change of 23.5\% of the budget slack. When Budget Slack is regressed on Emotional Exhaustion, the regression coefficient for Emotional Exhaustion is significant, indicating that Emotional Exhaustion has a significant impact on Budget Slack ( $\beta=0.334, p=0.000)$. This conclusion verifies $H_{1}$. On the basis of Step 2, add the moderating variable to form Step 3. From the Step 3, adding the interaction between emotional exhaustion and moral identity, the $\mathrm{R}^{2}$ value increases from $23.5 \%$ to $42.9 \%$, can significantly increase the budget slack by $19.4 \%$, and the $\mathrm{F}$ value increases significantly. When Budget Slack is regressed on Emotional Exhaustion and Moral Identity, the regression coefficient for interaction between Emotional Exhaustion and Moral Identity is significant, indicating that the interaction between emotional exhaustion and moral identity has a significant negative impact on budget slack. $(\beta=-0.459, \mathrm{p}=0.000)$. This conclusion preliminarily verifies $\mathrm{H}_{2}$.

Meanwhile, in order to further test the moderating effect of moral identity between emotional exhaustion and budget slack, we draw the moderating effect map according to the suggestions by Aiken and West (1991). The results are shown in Figure 1, describing the relationship between emotional exhaustion and budget slack at different levels of moral identity. When the level of moral 
Table 3. Tests for mediation effect-regression results.

\begin{tabular}{lccc}
\hline & \multicolumn{3}{c}{ Budget Slack } \\
\cline { 2 - 4 } & Step 1 & Step 2 & Step 3 \\
\hline Control & & & \\
$\quad$ Tenure & 0.242 & 0.227 & 0.197 \\
$\quad$ Ownership & 0.140 & 0.106 & 0.084 \\
$\quad$ Scale & 0.175 & 0.145 & 0.159 \\
Predictor & & & \\
$\quad$ Abusive supervision & & 0.322 & 0.448 \\
$\quad$ Emotional exhaustion & & -0.063 & -0.057 \\
Moderator & & & \\
$\quad$ Abusive supervision $\times$ Emotional exhaustion & & & -0.459 \\
$\delta \mathrm{R}^{2}$ & & 0.112 & 0.194 \\
$\mathrm{R}^{2}$ & 0.123 & 0.235 & 0.429 \\
Adjusted $\mathrm{R}^{2}$ & & & \\
$\mathrm{~F}$ & 0.116 & 0.225 & 0.420 \\
sig & 18.460 & 24.231 & 49.183 \\
\hline
\end{tabular}

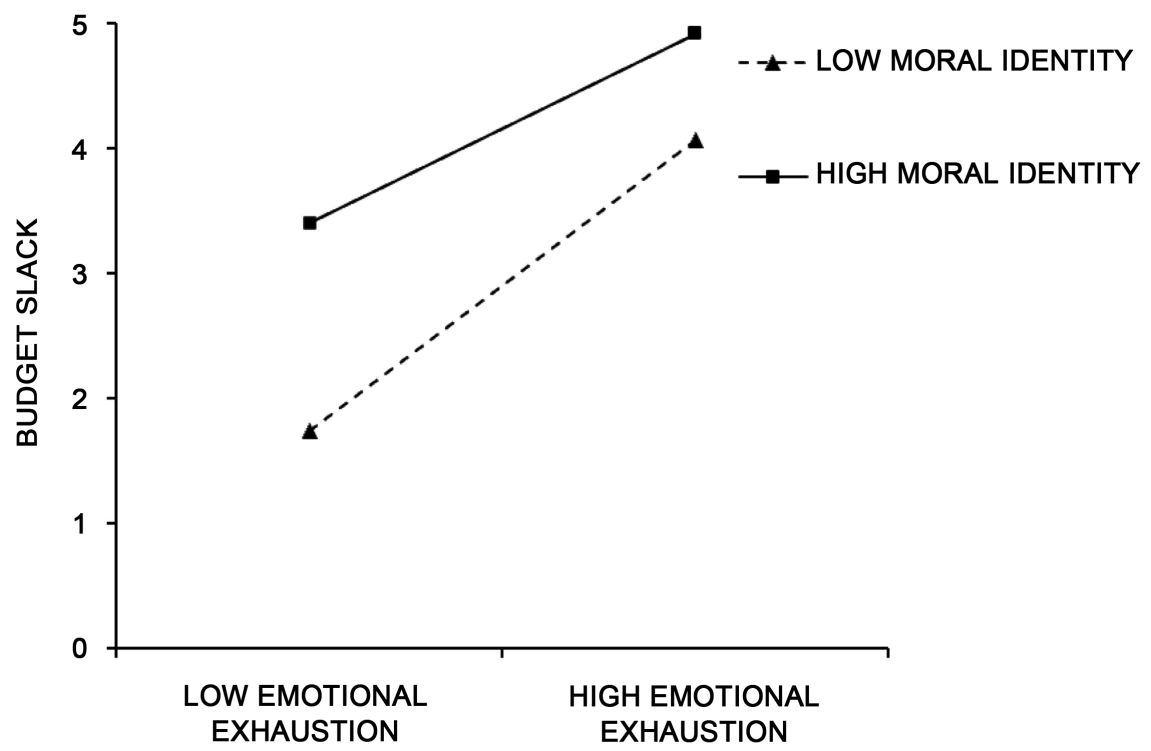

Figure 1. Interaction between emotional exhaustion and moral on budget slack.

identity is high, the effect of emotional exhaustion on budget slack is weaker, the line of high moral identity are more gentle than low moral identity, that is, the high level of moral identity inhibits the positive effect of emotional exhaustion on budget slack. Thus, there is strong support for $\mathrm{H}_{2}$.

\section{Discussion and Conclusions}

In the budget environment, it has been empirically demonstrated that there is a significant positive effect between emotional exhaustion and budget slack. That 
is, when subordinates are in emotional exhaustion, in order to avoid being punished or to gain their own benefit, subordinates tend to make more relaxed budget. This paper introduces the psychological state of emotional exhaustion into budget research and explores the causes of budget slack from internal psychology. The conclusion is consistent with that when the subordinates are in emotional exhaustion, their self-control ability will decline, and then leading to cheating behavior (Kim, Hwang, \& Lee, 2008).

Furthermore, it has been empirically demonstrated that moral identity plays a negative role in the positive relationship between emotional exhaustion and budget slack. This conclusion is consistent with the current research results on the moderating role of moral identity (Mitchell et al., 2017; Zhang \& Liao, 2017). The moral identity reflects the moral level of the individual, and the difference of moral identity will lead to the difference in behavior. In the budget, subordinates with high moral identity will weaken the influence of emotional exhaustion on budget slack; conversely, subordinates with low moral identity will enhance the influence of emotional exhaustion on budget slack. Subordinates with high moral identity care more about their own moral standards and attach importance to the moral attributes of their own behavior so that their superiors have a higher level of abusive supervision and are less likely to take budget slack. They prefer to take active communication with superiors to solve problems and avoid unethical behavior. The conclusion is consistent with that the research views of other scholars, that is, the moral identity can moderate individual antisocial behavior, and unethical behavior (Zeng, 2011; Stevens, 2002; Hobson et al., 2011).

Our results contribute to research that the budget slack behavior in emotional exhaustion. Exploring the influence path of emotion on budget slack emotion affect budgeting combined psychological theory, allows us to understand the mechanism of restraining budget slack from a deeper level. Our results also imply that the moral identity negatively moderates the relationship between emotional exhaustion and budget slack of subordinate. This provides a direction for restraining budget slack from moral identity.

There are several limitations. First, the measurement of budget slack behavior is used the attitude measurement method. However, the attitude tendency of individuals does not necessarily lead to their real behavior, according to the study of Mobley et al. (1979), attitude and real behavior also be regulated by other factors. Secondly, this paper mainly uses the network platform to issue the questionnaire, may be difficult to carry on the strict control to the department respondents are located, which may lead to the sample employees being in the sales department or the non-first-line production service department, which will have an impact on the empirical results.

Future research may consider measuring employees' real budget slack. For example, some scholars use the experimental method to measure the budget slack behavior and observe the budget slack behavior of the research sample by simulating the real situation (Brink et al., 2017; Brown et al., 2017). The advantage of experimental research is that it can easily control environmental variables, and it 
is convenient to investigate the influence of independent variables on dependent variables.

\section{Conflicts of Interest}

The authors declare no conflicts of interest regarding the publication of this paper.

\section{References}

Aiken, L. S., \& West, S. G. (1991). Multiple Regression. Beverly Hills, CA: Sage Publishing.

Aquino, K. F., \& Reed, A. I. (2000). Moral Identity and the Expanding Circle of Moral Regard toward Out-Groups. Journal of Personality and Social Psychology, 84, 1270-1286. https://doi.apa.org/doi/10.1037/0022-3514.84.6.1270

Aquino, K., \& Reed, A. I. (2002). The Self-Importance of Moral Identity. Journal of Personality \& Social Psychology, 83, 1423-1440. https://doi.apa.org/doi/10.1037/0022-3514.83.6.1423

Brink, A. G., Coats, J. C., \& Rankin, F. W. (2017). Deceptive Superiors and Budgetary Reporting: An Experimental Investigation. Journal of Management Accounting Research, 29, 79-91. https://doi.org/10.2308/jmar-51591

Brown, J. L., Fisher, J. G., Peffer, S. A., \& Sprinkle, G. B. (2017). The Effect of Budget Framing and Budget-Setting Process on Managerial Reporting. Journal of Management Accounting Research, 29, 31-44. https://doi.org/10.2308/jmar-51535

Chen, R., \& Qin, Q. (2011). Relationship between Emotional Labor and Depression and Anxiety: The Mediating Role of Emotional Exhaustion. Psychological Science, 34, 676679.

Davidson, D., \& Stevens, D. (2013). Can a Code of Ethics Improve Manager Behavior and Investor Confidence? An Experimental Study. The Accounting Review, 88, 51-74. https://doi.org/10.2308/accr-50272

Deng, D., Liu, H., Xie, H., \& Miao, X. (2014). The Role of External Control and SelfControl in Suppressing Budget Slack: An Experimental Study Based on Difference Investigation and Moral Cognition. Accounting Research, No. 4, 49-57+96.

Douthit, J., \& Stevens, D. (2015). The Robustness of Honesty Effect on Budget Proposals when the Superior has Rejection Authority. The Accounting Review, 90, 467-493. https://doi.org/10.2308/accr-50937

Golparvar, M. (2015). Unconventional Functions of Deviant Behaviors in the Relationship between Job Stress and Emotional Exhaustion: Three Study Findings. Current Psychology, 35, 269-284. https://doi.org/10.1007/s12144-014-9292-8

Hobson, J. L., Mellon, J. M., \& Stevens, D. E. (2011). Determinants of Moral Judgments Regarding Budgetary Slack: An Experimental Examination of Pay Scheme and Personal Values. Behavioral Research in Accounting, 23, 87-107. https://doi.org/10.2308/bria.2011.23.1.87

Ju, D., Qin, X., \& Xu, M. (2016). Boundary Conditions of the Emotional ExhaustionUnsafe Behavior Link: The Dark Side of Group Norms and Personal Control. Asia Pacific Journal of Management, 33, 113-140. https://doi.org/10.1007/s10490-015-9455-7

Kavussanu, M., Stanger, N., \& Ring, C. (2015). The Effects of Moral Identity on Moral Emotion and Antisocial Behavior in Sport. Sport, Exercise, and Performance Psychology, 4, 268-279. https://doi.apa.org/doi/10.1037/spy0000040 
Kim, S., Hwang, J., \& Lee, D. (2008). Prefrontal Coding of Temporally Discounted Values during Intertemporal Choice. Neuron, 59, 161-172. https://doi.org/10.1016/j.neuron.2008.05.010

Lawrence, E. R., \& Michele Kacmar, K. (2017). Exploring the Impact of Job Insecurity on Employees Unethical Behavior. Business Ethics Quarterly, 27, 39-70. https://doi.org/10.1017/beq.2016.58

Li, Y. X., \& Li, Y. M. (2006). Preliminary Discussion on the Evaluation Standard of Job Burnout. Psychological Science, 29, 148-150.

Libby, T., \& Murray Lindsay, R. (2011). Beyond Budgeting or Budgeting Reconsidered? A Survey of North-American Budgeting Practice. Management Accounting Research, 21, 56-75. https://doi.org/10.1016/j.mar.2009.10.003

Little, H. T., Magner, N. R., \& Welker, R. B. (2002). The Fairness of Formal Budgetary Procedures and Their Enactment Relationships with Managers Behavior. Group \& Organization Management, 27, 209-225. https://doi.org/10.1177\%2F10501102027002003

Liu, F., Li, J., \& Yang, L. (2017). Research on the Relationship between Corporate Social Responsibility, Moral Identity and Employee Organization Citizen Behavior. Chinese Soft Science, No. 6, 117-129.

Maslach, C., Jackson, S.E., Leiter, M.P., Schaufeli, W.B.I., \& Schwab, R.L. (1986). Maslach Burnout Inventory. Consulting Psychologists Press.

Maslach, C., Schaufeli, W. B., \& Leiter, M. P. (2001). Job Burnout. Annual Review of Psychology, 52, 397-422. https://doi.org/10.1146/annurev.psych.52.1.397

Mazar, N., Amir, O., \& Ariely, D. (2008). The Dishonesty of Hones People: A Theory of Self-Concept Maintenance. Journal of Marketing Research, 45, 633-644. https://doi.org/10.1509\%2Fjmkr.45.6.633

Merchant, K. A. (1985). Budgeting and the Propensity to Create Budgetary Slack. Accounting, Organizations and Society, 10, 201-210. https://doi.org/10.1016/0361-3682(85)90016-9

Merchant, K. A., \& Manzoni, O. (1989). The Achievability of Budget Targets in Profit Centers: A Field Study. In C. Emmanuel, D. Otley, \& K. Merchant (Eds), Readings in Accounting for Management Control (pp. 496-520). Boston, MA: Springer. https://doi.org/10.1007/978-1-4899-7138-8_23

Mitchell, M. S., Bear, M. D., Ambrose, M. L., Folger, R., \& Palmer, N. F. (2017). Cheating under Pressure: A Self-Protection Model of Workplace Cheating Behavior. Journal of Applied Psychology, 103, 54-73. https://doi.apa.org/doi/10.1037/apl0000254

Mobley, W. H., Griffeth, R. W., Hand, H. H., \& Meglino, B. M. (1979). Review and Conceptual Analysis of the Employee Turnover Process. Psychological Bulletin, 86, 493-522. https://content.apa.org/doi/10.1037/0033-2909.86.3.493

Onsi, M. (1973). Factor Analysis of Behavioral Variables Affecting Budgetary Slack. The Accounting Review, 48, 535-548.

Ormiston, M. E., \& Wong, E. M. (2013). License to Ill: the Effects of Corporate Social Responsibility and CEO Moral Identity on Corporate Social Irresponsibility. Personnel Psychology, 66, 861-893. https://doi.org/10.1111/peps.12029

Passini, S. (2016). Concern for Close or Distant Others: the Distinction between Moral Identity and Moral Inclusion. Journal of Moral Education, 45, 74-68.

https://doi.org/10.1080/03057240.2016.1156522

Reynolds, S. J., \& Ceranic, T. L. (2007). The Effects of Moral Judgment and Moral Identity on Moral Behavior: An Empirical Examination of the Moral Individual. Journal of Applied Psychology, 92, 1610-1624. 
https://doi.apa.org/doi/10.1037/0021-9010.92.6.1610

Schatzberg, J. W., \& Stevens, D. E. (2008). Public and Private Forms of Opportunism within the Organization: A Joint Examination of Budget and Effort Behavior. Journal of Management Accounting Research, 20, 59-81.

https://doi.org/10.2308/jmar.2008.20.1.59

Skarlicki, D. P., Van Jaarsveld, D. D., \& Shao, R. (2016). Extending the Multifocal Perspective: The Role of Supervisor Justice and Moral Identity in the Relationship between Customer Justice and Customer-Directed Sabotage. Journal of Applied Psychology, 101, 108-121. https://doi.apa.org/doi/10.1037/apl0000034

Stevens, D. E. (2002). The Effects of Reputation and Ethics on Budgetary Slack. Journal of Management Accounting Research, 14, 153-171. https://doi.org/10.2308/jmar.2002.14.1.153

Subramaniam, N., \& Mia, L. (2003). A Note on Work-Related Values, Budget Emphasis and Manager's Organisational Commitment. Management Accounting Research, 14, 389-408. https://doi.org/10.1016/j.mar.2003.07.001

Tayler, W. B., \& Bloomfield, R. J. (2011). Norms, Conformity, and Controls. Journal of Accounting Research, 49, 753-790. https://doi.org/10.1111/j.1475-679X.2011.00398.x

Tijdink, J. K., Vergouwen, A. C., \& Smulders, Y. M. (2014). Emotional Exhaustion and Burnout among Medical Professors; A Nationwide Survey. BMC Medical Education, 14, Article No. 183. https://doi.org/10.1186/1472-6920-14-183

Webb, R. A. (2002). The Impact of Reputation and Variance Investigations on the Creation of Budget Slack. Accounting Organization and Society, 27, 361-378.

https://doi.org/10.1016/S0361-3682(01)00034-4

Wen, Z., Zhang, L., \& Hou, J. (2006). Mediated Moderator and Moderated Mediator. Act Psychologica Sinica, 38, 448-452.

Wu, M., Shao, X., \& Sun, X. (2017). Relationship between Service-Oriented Leadership, Moral Identity and UPB. Applied Psychology, 23, 152-161.

Yang, J., \& Wang, X. (2015). Moral Leadership and Employee Unethical Behavior, Altruistic Behavior: the Mediating Role of Moral Evading. Psychological Science, 38, $693-$ 699.

Yang, J., Wang, X., Lu, L., \& Zhang, L. (2010). A Study on the Relationship between Moral Evasion and Academic Deception of College Students. Psychological Development and Education, 26, 364-370.

Yu, Z., Yuan, G., \& Liu, G. (2004). Research on the Framework of Budget Management System of Group. Accounting Research, No. 8, 21-28.

Zeng, X. (2011). Foreign Research Progress on Moral Identity. Journal of Chongqing Technology and Business University, 4, 20-25.

Zhang, F., \& Liao, J. (2017). Ethical Leadership and Ethical Issues Report: The Role of Moral Effectiveness and Moral Identity. Management Comments, 29, 94-105.

Zhang, L., Lin, Y. C., \& Zhang, L. (2014). Effects of Job Insecurity on Emotional Exhaustion: Moderating of Social Support. Scientific Research Management, 35, 91-98.

Zheng, Q., Ye, B., \& Cong, L. (2016). The Influence of Moral Evasion on College Students' Network Attack: The Mediating Role of Moral Identity and the Moderate of Gender. Chinese Journal of Clinical Psychology, 24, 714-716. 